\title{
Aspectos fundamentais da expansão por umidade: uma revisão Parte I: Aspectos históricos, causas e correlações
}

\author{
(F undamental aspects of the moisture expansion: a review \\ Part I: Historical aspects, reasons and correlations)
}

\author{
R. R. Menezes ${ }^{a}$, L. F. Campos ${ }^{b}$, G. de A. Neves ${ }^{b}$, H. C. Ferreira ${ }^{b}$ \\ ${ }^{a}$ CPGCEM, Laboratório de Síntese e Processamento de Materiais Cerâmicos, LaSP, \\ Universidade Federal de S. Carlos, S. Carlos, 13565-905, SP \\ ${ }^{b}$ Departamento de Engenharia de Materiais, Centro de Ciências e Tecnologia, \\ Universidade Federal de Campina Grande, Campina Grande, PB \\ rrmboca@iris.ufscar.br
}

\begin{abstract}
Resumo
A expansão por umidade de materiais cerâmicos (EPU) vem sendo observada e estudada desde o início do século passado. Muitos estudos reportaram falhas estruturais e gretamento de peças esmaltadas como conseqüência de falta de controle da EPU de produtos cerâmicos, enquanto, vários outros, dedicaram-se ao estudo de suas causas, relações com a composição e com as características de queima do produto cerâmico e aos métodos de determinação. No entanto, observa-se que grande parte desse conhecimento encontra-se de forma dispersa na literatura mundial, o que dificulta o estudo, entendimento e compreensão do fenômeno, além de minimizar a importância do assunto. Assim, este trabalho tem por objetivo fazer um levantamento dos estudos realizados a cerca da EPU, evidenciando os resultados mais relevantes da literatura. O texto aborda desde aspectos históricos e causas da EPU a possíveis correlações com a composição, temperatura de queima, absorção de água e área específica de corpos cerâmicos.

Palavras-chave: expansão por umidade, materiais cerâmicos.
\end{abstract}

\begin{abstract}
Moisture expansion (ME) of ceramic materials have being studied and observed since the beginning of the last century. Many studies reported the failure of structural ceramics and the crazing of glazed bodies as a consequence of the lack of control of the ME of ceramic products. While many other studies analyzed the reasons of the ME, its relations with the composition and firing characteristics of the ceramic body, and the methodologies for the determination of ME. However, this knowledge is dispersed in the world literature, making difficult the study and understanding of the phenomenon; moreover, it minimizes the importance of the subject. This work aims to make a review of the studies on the moisture expansion of ceramic bodies, emphasizing the most relevant results. The text consists on the historic aspects, the reasons of the ME and the correlations of the ME with composition, firing temperature, water absorption and surface area of ceramic bodies.
\end{abstract}

Keywords: moisture expansion, ceramic materials.

\section{EXPANSÃO POR UMIDADE (EPU)}

EPU é o termo técnico utilizado para designar a expansão sofrida por materiais cerâmicos quando em contato com a água na forma líquida ou de vapor. Essa expansão geralmente ocorre lentamente e é relativamente pequena. Mesmo assim, pode levar ao gretamento de peças esmaltadas e ao comprometimento estrutural dos corpos cerâmicos, caso as tensões geradas pela deformação contida das peças excedam os limites de resistência dos materiais.

No caso dos revestimentos esse efeito pode comprometer a aderência das placas cerâmicas ao contrapiso e dessa forma levar ao seu destacamento, caso as forças de ligação entre os constituintes do revestimento sejam "fracas", ou a possíveis danos físicos nos constituintes do sistema, caso as ligações sejam "fortes" [1]. Já nas alvenarias pode levar ao aparecimento de trincas nos tijolos [2].

Junto com o ataque de sais a EPU é a causa mais comum de deterioração de tijolos, telhas e placas cerâmicas de revestimento, em todo o mundo, tendo atraído a atenção de cientistas desde o final dos anos 20, notadamente na África do Sul, Austrália, certos países da Europa e Estados Unidos [3, 4].

Quando a deformação oriunda da EPU é contida, ocorre a geração de uma tensão, que de acordo com a lei de Hooke, é diretamente proporcional ao módulo de elasticidade do material e à variação dimensional do material, tal como 
indicado na equação (A):

$$
\mathrm{F}=\mathrm{E} d
$$

onde $\mathrm{F}$ é a tensão de compressão em MPa, E o módulo de elasticidade da cerâmica em MPa, e $d$ a deformação da cerâmica em cm/cm (EPU).

Como o módulo de elasticidade, E, da cerâmica varia entre 30000 e $70000 \mathrm{MPa}$, e a EPU, $d$, varia em geral entre zero e $0,001 \mathrm{~cm} / \mathrm{cm}(1 \mathrm{~mm} / \mathrm{m})$, avaliam os especialistas, que seu produto, ou seja, o esforço $\mathrm{F}$, nunca pode superar $35 \mathrm{MPa}$, já que, quanto maior o módulo $\mathrm{E}$, menor a deformação, mesmo que a deformação do conjunto de peças seja totalmente contida [5].

Porém, 40 a $60 \%$ desse esforço (em projetos ortodoxos) são absorvidos pela própria cerâmica e seu rejunte (no caso de revestimentos, já no caso das alvenarias, a argamassa e o cimento teriam essa função), devido às suas elasticidades ou compressibilidades. A argamassa de assentamento trabalhando à tração absorve mais uma parte, de modo que o esforço líquido residual atuante sobre a capa cerâmica não ultrapassa $18 \mathrm{MPa}$, tal como reconhecem os estudiosos da matéria [5]. Esta é a grandeza do esforço que precisa ser anulada para que a capa cerâmica não "exploda” por flambagem, o fenômeno conhecido por levantamento, destacamento, estufamento, ou "pop up". Vale salientar que estudos advogam que até $70 \%$ do esforço devido a EPU do corpo cerâmico pode ser absorvido apenas pela própria cerâmica e o rejunte [6].

Sabendo o esforço, pode-se estimar a EPU máxima que pode ocorrer para que não haja possíveis danos ao material cerâmico. Se por segurança tomamos um módulo, E, bem baixo, digamos, $30000 \mathrm{MPa}$, deduzimos que a deformação será $d=18 / 30000=0,0006 \mathrm{~cm} / \mathrm{cm}=0,6 \mathrm{~mm} / \mathrm{m} \mathrm{[5]}$.

Deve-se ressaltar que a EPU de peças cerâmicas não é um fenômeno que necessariamente conduz a falhas ou danos, e sim, que existe uma grande margem de segurança que varia muito de projeto para projeto. Portanto, a deformação indicada acima é apenas uma referência acerca da referida expansão. Além disso, a EPU de tijolos e placas de revestimento é apenas um dos vários fatores que contribuem para o movimento diferencial total da estrutura, os outros são; movimento térmico na alvenaria, retração da argamassa, movimento térmico da estrutura de suporte, fluência e retração no concreto, contrações elásticas, etc. Em casos típicos de EPU, esta pode representar até $15 \%$ do total do movimento diferencial [7].

No que se refere a peças esmaltadas, o movimento diferencial entre a base e o esmalte pode conduzir ao gretamento do vidrado. O gretamento do vidrado pode ser definido como um defeito que ocorre em peças cerâmicas vidradas, que se apresenta como um sistema de trincas no vidrado. Este defeito é oriundo de tensões de tração no vidrado, que a medida que aumentam provocam sistemas de trincas cada vez mais finos [8]. O gretamento pode se manifestar de diferentes formas. A maioria das vezes chega até a superfície em forma de pequenas fissuras visíveis com solução aquosa de azul de metileno (ou outro corante adequado), outras, vezes as fissuras permanecem ocultas dentro da interface suporte-esmalte sem chegar à superfície.

Os materiais cerâmicos, via de regra, apresentam uma resistência à tração consideravelmente menor do que à compressão. Por outro lado, a camada de vidrado tem uma espessura muito menor que a base e, portanto, principalmente por causa disso, possui uma resistência mecânica inferior. Assim sendo, é conveniente que as expansões térmicas da base e do esmalte sejam ajustadas de modo que o esmalte fique sob ligeira compressão após a queima, o que é conhecido como acordo massa-esmalte.

Se o acordo massa-esmalte não for ajustado corretamente, pode dar origem ao gretamento se o coeficiente de expansão térmica do esmalte for maior que o da base, ou ao lascamento, se o coeficiente de expansão térmica do esmalte for muito inferior ao da base [9].

O gretamento pode ser subdividido em gretamento imediato e gretamento retardado. $\mathrm{O}$ gretamento imediato surge quando o vidrado a temperatura ambiente é tracionado pelo suporte a ponto de ocorrer o aparecimento de trincas, sendo observado logo após a saída do forno ou pouco tempo depois. O gretamento retardado ocorre quando a deformação sofrida pelo biscoito devido à umidade adsorvida (EPU) e/ ou retração do cimento ou argamassa de fixação (no caso de revestimentos), transforma o esforço de compressão a que estava inicialmente submetido o vidrado em um esforço de tração [10].

Acreditava-se que o gretamento retardado ocorria devido às deformações geradas por tensões no vidrado, que provocavam sua falha por fadiga. Essa hipótese foi desconsiderada [11], quando se comprovou que eram as alterações das dimensões do corpo cerâmico quem provocavam o gretamento retardado. Posteriormente [12] várias composições de vidrados (algumas comerciais) foram analisadas durante cinco anos, comprovando-se que, se os corpos cerâmicos forem mantidos fora do alcance da umidade não há alterações nas suas dimensões e nem gretamento retardado.

A retração do cimento ou argamassa sempre foi considerada como a principal causa do gretamento de revestimentos cerâmicos, mesmo quando não se tinha o perfeito entendimento deste mecanismo de gretamento [13], sendo indicado que a EPU de peças cerâmicas, mesmo quando mantidas imersas em água, era sempre um fator secundário quando comparada com a retração do cimento. Todavia hoje, com a utilização de argamassas e adesivos especialmente desenvolvidos para o assentamento de revestimentos e com toda a normalização que rege o setor, o efeito da sua retração passa a ter uma influência bem menor no gretamento retardado de revestimentos cerâmicos, bem como no estufamento das peças, passando a ser as falhas de assentamento e execução de projetos, juntamente com 
a EPU as suas principais causas. Como exemplo, têm-se trabalhos [14], que observaram que cerca de $80 \%$ das falhas de estufamento em revestimentos no Reino Unido era devido a erros de design ou a práticas de assentamento incorretas.

No entanto, a EPU continua sendo uma das principais causas, se não a principal, do gretamento de peças vidradas de uso doméstico, tal como pratos, xícaras, canecas e louças em geral, tal como revelam estudos recentes $[15,16]$.

\section{Breve histórico}

O fenômeno de EPU de produtos argilosos foi inicialmente discutido na literatura cerâmica por volta de 1926 por Merritt e Peters [17], sendo a primeira referência à expansão de tijolos feita por Palmer em 1931 [18]. É citado que já em 1907 há menção na literatura que tijolos inadequadamente queimados adsorviam água e se rehidratavam, enquanto corpos "bem" queimados apenas apresentavam água mecanicamente ligada. No entanto, a indústria da construção civil só veio a tomar ciência do assunto em 1947 com a publicação de um estudo do Instituto de Engenheiros da Austrália sobre os danos e perigo da EPU em tijolos e dutos de esgotos [19].

Em 1928 Schurecht [11], estudando o gretamento retardado de corpos cerâmicos esmaltados, foi o pioneiro na utilização de ensaio em autoclave para acelerar a expansão das peças cerâmicas, concluíndo que o gretamento retardado devia-se à expansão do corpo cerâmico e não a falha por fadiga do vidrado, evidenciando também a existência de correlações entre a expansão de corpos cerâmicos autoclavados e sua expansão natural. Dando continuidade às pesquisas iniciadas em 1928, Schurecht e Pole [20] foram pioneiros no estudo do efeito da composição dos corpos cerâmicos na sua EPU, tendo observado a influência de silicatos amorfos no aumento da EPU e da adição de aditivos, como carbonatos de cálcio e magnésio, na sua redução. Esses autores evidenciaram também que o grau de vitrificação dos corpos cerâmicos tinha influência na suas expansões.

Holscher em 1931 [21], analisando o comportamento de argilas frente ao ensaio em autoclave, também observou a influência da composição sobre a expansão de corpos cerâmicos quando submetidos a ensaio de autoclavagem, mencionando que corpos que possuíam feldspato na sua formulação apresentavam expansão maior que as cerâmicas cuja formulação apresentava apenas argilas. Neste mesmo trabalho, Holscher mostrou que compostos não aquosos na forma líquida, tais como parafina e xileno, também podem causar a expansão dos corpos cerâmicos, mesmo que em amplitude inferior à causada pela água.

Seguindo os estudos da influência da EPU no gretamento do vidrado, Treischel em 1935 [22] foi um dos primeiros autores a analisar a expansão de revestimentos cerâmicos comerciais, enfatizando que especial atenção deveria ser dedicada à interação vidrado-biscoito a fim de se evitar o gretamento, e que os estudos deviam deter-se mais na expansão conjunta do vidrado e do corpo cerâmico, e não tanto nas suas expansões individuais.

No período entre 1926 e 1952 cerca de 37 artigos abordando a EPU de corpos cerâmicos foram publicados; todavia sua preocupação centrava-se no gretamento do vidrado de louças e revestimentos cerâmicos. Mesmo com alguns artigos dedicando-se aos danos da EPU em tijolos, apenas por volta 1952 essa questão ganhou uma maior evidência.

Em 1954 McBurney [23] publicou um artigo atribuindo as falhas estruturais de três construções norte-americanas à EPU dos produtos argilosos utilizados. Em 1955, Smith [24] introduziu a teoria que a EPU era causada pelo abaixamento da energia superficial dos corpos quando a umidade era adsorvida à sua superfície. No mesmo artigo Smith ainda apresentava evidências experimentais que confirmavam sua teoria. Em 1959 Young e Brownell [25] publicaram um artigo complementar ao de Smith, no qual analisaram o comportamento de corpos cerâmicos frente à composição química e relacionaram os resultados com a natureza das fases formadas.

A EPU tornou-se um sério problema na Austrália na década de 50 e foi, por isso, extensivamente estudada pelos institutos de pesquisa australianos, que analisaram efeitos de composição e microestrura sobre a EPU e métodos de ensaios para sua determinação, chegando a efetuar estudos [26] abordando o tratamento de tijolos, a fim de acelerar sua EPU antes do uso. Dentre as instituições australianas, destaca-se o Commonwealth Scientific and Industrial Research Organization (CSIRO), Division of Building Research (DBR), que, em conjunto com os demais centros de pesquisa australianos, perfizeram a maioria das publicações da literatura mundial abordando a EPU no período de 1955 até os dias atuais [27].

Em seguida, muitos estudos se dedicaram à cinética da expansão, buscando modelos matemáticos que explicassem o comportamento dos corpos cerâmicos frente à umidade, seja em tratamento com autoclave, em imersão em água, em ambiente saturado com vapor de água (mas à pressão atmosférica) ou ao ar livre. Baseando-se nesses modelos, tentaram prever a expansão futura dos corpos cerâmicos quando em serviço. Simultaneamente, vários pesquisadores passaram a estudar a metodologia mais adequada para determinar a expansão sofrida pelos corpos cerâmicos em serviço e prever as suas expansões futuras. Nessas pesquisas foram analisados, a velocidade de aquecimento na requeima, a temperatura máxima de requeima, o tempo de permanência nessa temperatura, bem como qual o tipo de ensaio (fervura, autoclavagem, ambiente saturado com vapor de água) que fornece os valores mais realistas sobre a expansão futura dos produtos cerâmicos. Tendo esses estudos se encaminhado para as normalizações hoje existentes, todavia, muitas divergências ainda existem quanto a esses procedimentos, tanto no que se refere aos ciclos de requeima como ao tipo de ensaio para prever expansões futuras. 
A partir de 1999, o Departamento de Engenharia de Materiais (DEMa) da Universidade Federal de Campina Grande (UFCG), passou a se dedicar ao estudo da EPU, em virtude da falência estrutural de três prédios situados na Grande Recife (PE), sendo evidenciado a EPU como uma das possíveis causas da ruína dos edifícios. Dando continuidade aos estudos sobre a EPU de corpos cerâmicos, o DEMa realizou uma série de publicações abordando a EPU de tijolos pernambucanos [28, 29], de tijolos produzidos na Paraíba [30] e de placas cerâmicas para revestimento comercializadas na região nordeste [31-36].

\section{Origem da expansão por umidade (EPU)}

Analisando a atração intermolecular, a superfície de um sólido possui o que para os líquidos é chamada tensão superficial, e isto é responsável por uma compressão para o interior do sólido. Se a água ou outro líquido é adsorvido, esta adsorção irá reduzir a energia superficial do sólido e, consequentemente, a compressão dentro do sólido. Quando esta tensão é reduzida, o sólido comporta-se elasticamente e expande [24]. Assim, se a molécula de água é atraída mais fortemente pela superfície do material que por outras moléculas de água, ela será adsorvida à superfície e a expansão ocorrerá. A magnitude dessa expansão dependerá da magnitude da redução da energia superficial e também do módulo de elasticidade do sólido. Superfícies que têm um grande número de valência insaturada vão, assim, sofrer maiores reduções na energia superficial e, sendo os outros fatores constantes, irão produzir maiores EPUs. Outro fator a considerar é que quanto maior a superfície interna do sólido, maior será a redução na energia superficial por unidade de volume, e maior a expansão [24].

A superfície interna (acessibilidade à água), a energia específica e o módulo elástico do produto são os fatores que determinam a EPU. Os constituintes do produto cerâmico têm estreita relação com esses fatores, sendo esses constituintes convenientemente classificados de forma geral em amorfos, cristalinos e vítreos.

Os materiais amorfos sempre têm uma grande área específica, a exemplo da sílica amorfa, constituinte comum em cerâmicas tradicionais, e elevada energia superficial, contribuindo em muito para a EPU [24].

Os materiais cristalinos têm área específica menor que a dos amorfos, bem como bem menos valências insaturadas na superfície. Já os materiais vítreos não possuem uma elevada área específica, possuem uma energia superficial relativamente baixa, mas permitem a difusão dos íons modificadores de estrutura para a superfície. Esses íons, quando lixiviados pela água, são removidos e substituídos por íons $\mathrm{H}^{+}$, ocorrendo a formação de superfícies semelhantes à dos materiais amorfos. Com a lixiviação pode ocorrer também a abertura de poros que estavam anteriormente selados, aumentando a superfície acessível à água e, por conseguinte, a EPU da peça cerâmica [24].
Os minerais que entram na composição das matériasprimas dos corpos cerâmicos contêm água em suas moléculas, porém no processo de queima durante a fabricação essa água é volatilizada, e com a continuação do processo de queima ocorre a formação de constituintes amorfos, vítreos e cristalinos. Todavia logo após o processo de queima, e durante meses e anos após a fabricação, ocorrerá a rehidratação por adsorção de água, principalmente dos constituintes amorfos e vítreos. A hidratação por adsorção provoca um aumento de volume dos compostos presentes, expandindo o corpo cerâmico [37].

Estudos relativos à natureza do processo de adsorção e ao efeito de fatores externos sobre ele, evidenciaram que quatro fatores são de grande influência: o tempo de exposição, a natureza da exposição, as características físicas do corpo e a composição química do corpo [14]. Como exemplo têm-se estudos [38, 39] que demonstraram a influência da umidade ambiente na EPU de corpos cerâmicos, sendo observado que corpos mantidos em umidade relativa de $90 \%$ expandiam cerca de $20 \%$ a mais que aqueles mantidos em $65 \%$.

\section{Influência da temperatura de queima}

Vários estudos sobre o efeito da composição do corpo e da temperatura de queima na expansão por umidade, concluíram que para uma dada composição a expansão diminui com o aumento da temperatura de queima. No entanto, a relação exata entre a EPU e a temperatura de queima varia de acordo com a composição e com a estrutura dos diferentes corpos cerâmicos [40]. Assim, os estudos acerca da relação entre EPU e temperaturas de queima expressam comportamentos associados a matérias-primas específicas, sendo a maioria dos estudos relacionados às argilas cauliníticas.

Estudos em 1958 [41], usando argila caulinítica, foram os primeiros a observar o comportamento de EPU de um corpo cerâmico em função da temperatura de queima, verificando que à medida que aumentava a temperatura, havia um decréscimo da EPU, atingindo um mínimo de aproximadamente $1070{ }^{\circ} \mathrm{C}$, seguindo-se de um pequeno aumento até $1100^{\circ} \mathrm{C}$ e posterior decréscimo. A Fig. 1 ilustra os resultados obtidos [41].

Em 1959 [25], também usando argilas basicamente cauliníticas, observou-se um comportamento bastante semelhante ao indicado anteriormente [39], com um decréscimo da EPU a medida que a temperatura aumentava, chegando a um mínimo em $850{ }^{\circ} \mathrm{C}$, seguindo-se de um pequeno aumento entre 900 e $950{ }^{\circ} \mathrm{C}$ (chamada de região de máxima EPU) e posterior decréscimo. Concluindo-se que, de forma geral, aumentos na temperatura de queima conduziriam a uma redução de EPU. Esses resultados [25] diferiram basicamente dos anteriores [41] por apresentarem um máximo de EPU bem mais acentuado e em uma temperatura inferior, o que se deveu provavelmente a diferenças mineralogias nas matérias-primas. A Fig. 2 ilustra a curva de EPU versus temperatura obtida [25].

A curva obtida em [25], Fig. 2, passou a ser utilizada 
como referência no que se refere ao comportamento de EPU de corpos a base de argilas cauliníticas, frente à temperatura de queima. Em seguida [42], utilizando-se argilas cauliníticas e argilas cujos argilominerais predominantes eram caulinita e montmorilonita e caulinita e mica moscovita, observou-

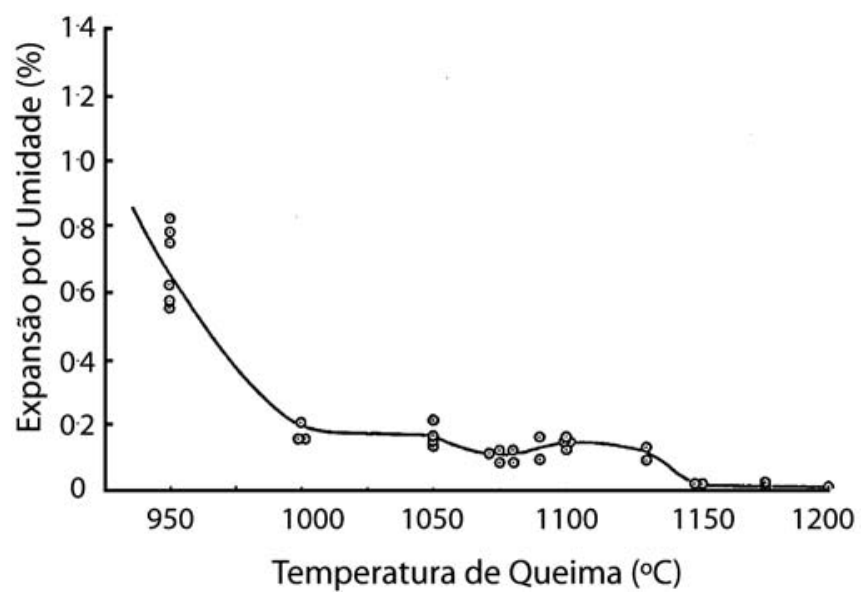

Figura 1: Relação entre temperatura de queima e EPU após autoclavagem por $96 \mathrm{~h}$ a $200{ }^{\circ} \mathrm{C}$ [41].

[Figure 1: Firing temperature versus ME after autoclaving for $96 \mathrm{~h}$ at $200{ }^{\circ} \mathrm{C}$ [41].]

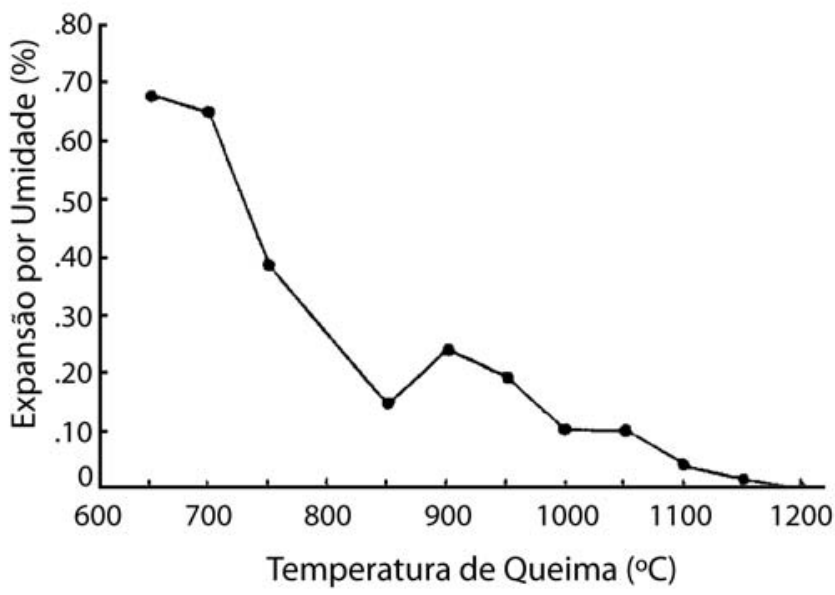

Figura 2: Efeito da temperatura de queima na EPU (em autoclave) [25].

[Figure 2: Effect of the firing temperature on the $M E$ (autoclaved) [25].]

se um comportamento semelhante ao descrito anteriormente $[25,41]$, com todas os corpos cerâmicos apresentando o mesmo comportamento de elevação da EPU a partir de um mínimo, passando por um máximo e decrescendo em seguida com o aumento da temperatura de queima.

A fim de evidenciar que o comportamento da expansão frente à temperatura de queima realmente depende das matérias-primas, foram efetuados estudos [43] utilizandose uma composição a base de caulinita, quartzo e mica, verificando-se um pico de expansão a aproximadamente $1000{ }^{\circ} \mathrm{C}$ independentemente do tipo e do tempo do tratamento de autoclagem dos corpos cerâmicos. A Fig. 3 ilustra as curvas de EPU obtidas [43].

O comportamento da EPU frente à temperatura de queima ainda não é totalmente explicável. Alguns autores atribuem o intervalo com maiores valores de EPU à formação de um espinélio de alumínio e silício com liberação de sílica amorfa a aproximadamente $925^{\circ} \mathrm{C}$ e à transformação do espinélio em mulita, com mais liberação de sílica amorfa na faixa de temperatura entre 1050 e $1100{ }^{\circ} \mathrm{C}$. No entanto a formação da fase espinélio só foi observada em caulinitas bem cristalizadas. Ao que tudo indica, a única certeza está no fato de haver a formação de uma fase amorfa durante o aquecimento que é responsável pelo pico de EPU.

\section{Influência da composição mineralógica}

Os pioneiros [20] na tentativa de correlacionar a EPU com a composição dos corpos cerâmicos, observaram uma estreita relação entre os aditivos utilizados nas pesquisas e a EPU, com destaque para os carbonatos de cálcio e magnésio,

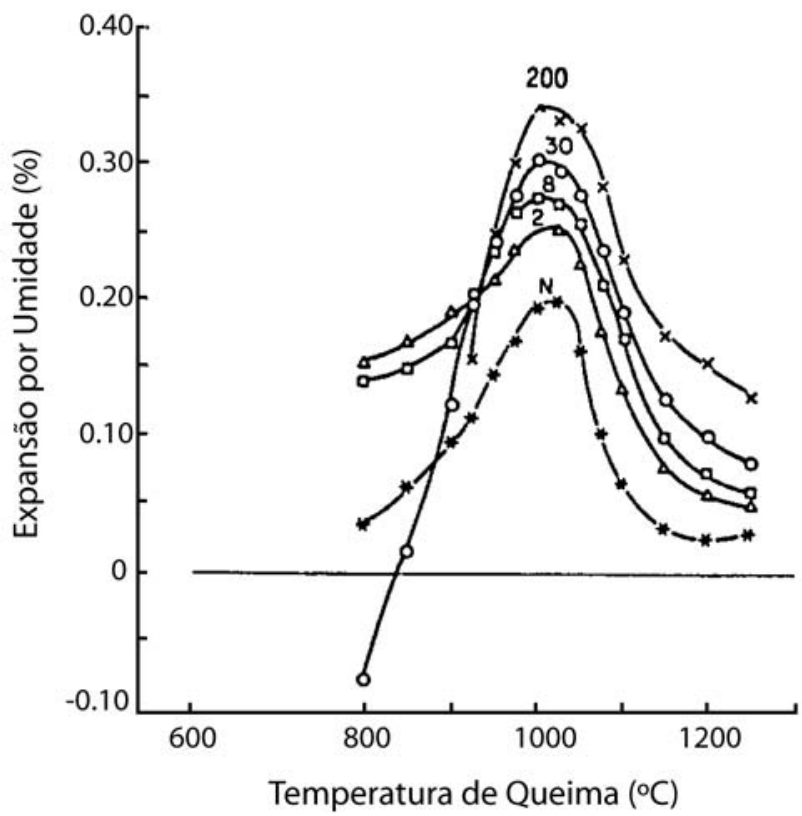

Figura 3: Efeito da temperatura na EPU do corpo cerâmico: $\mathrm{N}$ - expansão natural após 90 dias; 2, 8, 30 e 200 h de tratamento em autoclave [43].

[Figure 3: Effect of firing temperature on the ME of ceramic body: $N$ natural expansion after 90 days; autoclaved for 2, 8, 3 and $200 \mathrm{~h}$ [43].]

que propiciaram redução da EPU. Em seguida, em estudos [21] analisando a influência da composição química de argilas na EPU do corpo cerâmico quando submetido a ensaio em autoclave, observou-se que as variações de dimensões eram bem mais acentuadas em corpos que continham feldspato como uma de suas matérias-primas, do que em 
corpos cujas matérias-primas eram apenas argilas. Sendo enfatizado ainda, que, a composição do corpo cerâmico é uma consideração mais importante que sua absorção de água quando se requer indicações do comportamento da EPU, após autoclavagem. Estas observações foram ratificadas posteriormente [44], chegando-se a conclusões semelhantes ao se estudar mais detalhadamente a adição de feldspato a massa cerâmica. Com a continuidade das pesquisas, evidenciou-se [45] haver um efeito aditivo na EPU quando várias argilas eram incorporadas na formulação da massa cerâmica, provavelmente devido às suas composições químicas e formação de eutéticos.

Após os estudos iniciais, vários outros foram realizados objetivando analisar sistematicamente a influência de adições à massa cerâmica sobre a EPU dos produtos. Nesta linha o primeiro foi realizado em 1958 [41], sendo analisado o efeito da adição dos carbonatos de sódio, potássio, bário e cálcio a corpos cerâmicos autoclavados, verificando que a EPU aumentou quando da adição de carbonato de sódio e/ou potássio à massa, atribuindo esse efeito à formação de fase vítrea em baixas temperaturas. Neste estudo foi observada também, a formação de nefelina $\left(\mathrm{Na}_{2} \mathrm{O} \cdot \mathrm{Al}_{2} \mathrm{O}_{3} \cdot 2 \mathrm{SiO}_{2}\right)$, nas composições contendo sódio, e a presença de feldspato potássico $\left(\mathrm{K}_{2} \mathrm{O} \cdot \mathrm{Al}_{2} \mathrm{O}_{3} \cdot 6 \mathrm{SiO}_{2}\right)$ e anortita $\left(\mathrm{CaO} \cdot \mathrm{Al}_{2} \mathrm{O}_{3} \cdot 2 \mathrm{SiO}_{2}\right)$, nas composições em que foram adicionados carbonatos de potássio e cálcio respectivamente. E que a adição de $\mathrm{CaCO}_{3}$ provoca uma redução da EPU, tal como observado anteriormente [20], sendo esse efeito creditado a formação da fase cristalina anortita.

\section{Influência da adição de $\mathrm{CaCO}_{3}$ e $\mathrm{MgCO}_{3}$}

Posteriormente em vários outros estudos foi detalhada a influência da adição de $\mathrm{Ca}$, bem como de $\mathrm{Mg}$, na EPU, evidenciando os seus efeitos com relação à temperatura de queima e percentual utilizado, ressaltando que o grau de influência está também muito relacionado com a formulação da massa cerâmica e com as características das matérias-primas e de processamento. Assim, por exemplo, uma dada percentagem de carbonato de cálcio (ou de magnésio) pode alterar de formas diferentes a EPU de uma dada massa cerâmica, podendo aumentar ou diminuir a EPU do corpo cerâmico [46, 47].

Pesquisadores [48] observaram que a adição de calcita (15\%) à massa cerâmica praticamente eliminou a EPU, todavia, a utilização de elevados teores (20 e 25\%) conduzia a um aumento da $\mathrm{EPU}$, provavelmente devido à presença de $\mathrm{CaO}$ livre, que ao reagir com a água, se hidrata e expande. Verificaram também que composições contendo mais que $5 \%$ de calcita, não apresentaram variações significativas da EPU com a temperatura de queima. A análise por difração de raios $\mathrm{X}$ indicou a presença de mulita $\left(3 \mathrm{Al}_{2} \mathrm{O}_{3} \cdot 2 \mathrm{SiO}_{2}\right)$ e quantidade crescente de anortita de acordo com o teor de $\mathrm{CaO}$, e a partir de $10 \%$, ghelenita $\left(2 \mathrm{CaO} \cdot \mathrm{Al}_{2} \mathrm{O}_{3}\right.$. $\left.\mathrm{SiO}_{2}\right)$ e wollastonita $\left(\mathrm{CaO} \cdot \mathrm{SiO}_{2}\right)$. A formação de fases de cálcio, como ghelenita, anortita e a wollastonita afeta significativamente a EPU, pois estas fases resultam da reação do óxido de cálcio, proveniente da decomposição da calcita, com as fases amorfas provenientes das transformações do material argiloso durante 0 aquecimento, fases essas, principais responsáveis pela EPU.

Em outros estudos foi evidenciado que a diminuição da EPU com a adição de $\mathrm{CaCO}_{3}$, é mais significativa em temperaturas elevadas $\left(1200{ }^{\circ} \mathrm{C}\right)$, em virtude do aumento da proporção das fases cristalinas mulita e anortita com a elevação da temperatura de queima. Assim, um produto final mais cristalino, com menos fases amorfas e vítreas explicaria a menor EPU nestes corpos [49].

Analisando a influência do $\mathrm{MgCO}_{3}$, foi indicado que na faixa de temperatura de 1050 a $1125^{\circ} \mathrm{C}$ ocorre um aumento da EPU com o aumento do $\mathrm{MgCO}_{3}$. Quando submetido a temperaturas mais elevadas $\left(1200{ }^{\circ} \mathrm{C}\right)$ há uma diminuição da EPU com o aumento do $\mathrm{MgCO}_{3}$. A constituição mineralógica dos corpos de prova com adição de $\mathrm{MgCO}_{3}$ era formada, antes da queima, de caulinita, quartzo, mica moscovita, e magnesita. Após a queima observou-se a presença de quartzo, mulita, periclásio $(\mathrm{MgO})$ e a $1200{ }^{\circ} \mathrm{C}$ a presença de uma pequena quantidade de safirina ( $\left.4 \mathrm{MgO} .5 \mathrm{Al}_{2} \mathrm{O}_{3} \cdot 2 \mathrm{SiO}_{2}\right)$. Em outros trabalhos [50] também é indicada a presença de fosterita $\left(2 \mathrm{MgOSiO}_{2}\right)$. As novas fases são oriundas da reação do $\mathrm{MgO}$ com a metacaulinita e com o quartzo, todavia a reação do óxido de magnésio foi muito pequena com os constituintes amorfos para formar fases cristalinas, permanecendo na forma de óxido livre, passível de hidratação e de expansão. Uma maior proporção da fase mulita e a presença de safirina a $1200^{\circ} \mathrm{C}$ explica o fato de ocorrer uma menor EPU nesta temperatura [49].

À semelhança dos estudos mencionados acima, outros autores [51] observaram que há uma expansão devido a reação entre a água e o $\mathrm{CaO}$ e o $\mathrm{MgO}$ e que esta expansão provoca microtrincas no material, destruindo sua elasticidade e a capacidade de recuperar as suas dimensões com o reaquecimento e perda da água adsorvida, chegando a produzir expansões maiores que a própria EPU. Assim, fica evidente que os óxidos formados pela decomposição do $\mathrm{CaCO}_{3}$ e $\mathrm{MgCO}_{3}$, podem reagir com a água e formar os hidróxidos correspondentes, provocando expansão. Então, para que os benefícios de redução da EPU possam ser alcançados é preciso garantir que as reações com os constituintes das matérias-primas, durante a queima, consumam todo o carbonato adicionado. A calcita geralmente perde o $\mathrm{CO}_{2}$ por volta de $900{ }^{\circ} \mathrm{C}$ e a dolomita (composta por $\mathrm{CaCO}_{3}$ e $\mathrm{MgCO}_{3}$ ) entre 700 e $900{ }^{\circ} \mathrm{C}$. Entretanto as temperaturas nas quais essas decomposições ocorrem e a velocidade com que as reações com os demais constituintes da massa se processam dependem, dentre outros fatores, do grau de cristalinidade, da granulometria, da proximidade da mistura (com as demais matérias primas que compõem a massa), do grau de compactação, da atmosfera do forno e do ciclo de queima [2]. Devendo-se então levar em conta não apenas a temperatura de queima, mas sim, todas as possíveis variáveis da cinética de reação.

Outro ponto que pode ser mencionado com relação à utilização dos carbonatos de cálcio e magnésio é o fato de poderem propiciar elevada porosidade a peça (dependendo da temperatura de queima), e uma peça porosa é muito acessível 
à água, hidratando-se as fases amorfas e vítreas presentes, o que pode causar um aumento de tamanho da peça queimada, e originar curvaturas ou gretamentos no vidrado. Por isso, é necessário que as peças queimadas apresentem uma elevada proporção de fases cristalinas e pequena quantidade de fases amorfas, para que as adições de carbonatos não tenham efeito danoso ao produto [52]. Esta condição foi comprovada em estudos [50] que mostraram que peças com elevada porosidade podem apresentar EPU menor que peças com baixa porosidade, em virtude da presença das fases cristalinas oriundas da adição de carbonatos de cálcio e magnésio à massa cerâmica.

Influência da adição de álcalis e das relações aluminal sílica e álcalis/alumina

A influência da composição química de caulins sobre a EPU, bem como o comportamento da EPU frente à adição de álcalis e quartzo aos caulins foram profundamente analisados em 1959 [25]. O estudo indicou haver correlações entre a EPU e a composição química dos caulins (ressaltando que os autores trabalharam com um valor fixo de $8 \%$ de absorção de água) conforme ilustrado nas Figs. 4 e 5. Observa-se que conforme a razão alumina/sílica aumenta há um decréscimo da expansão e que com o aumento da relação álcalis/ alumina há uma elevação da EPU, sendo esta última relação confirmada em outros trabalhos [42, 53].

Quanto à influência da adição de álcalis, a Fig. 6 ilustra os resultados obtidos [25], utilizando sódio e potássio em proporção equimolar. Pode-se observar um aumento acentuado da expansão com a elevação do teor de alcalinos e a intensificação de um máximo de expansão a $1000{ }^{\circ} \mathrm{C}$ conforme se aumenta a quantidade de álcalis, provavelmente devido à formação de uma

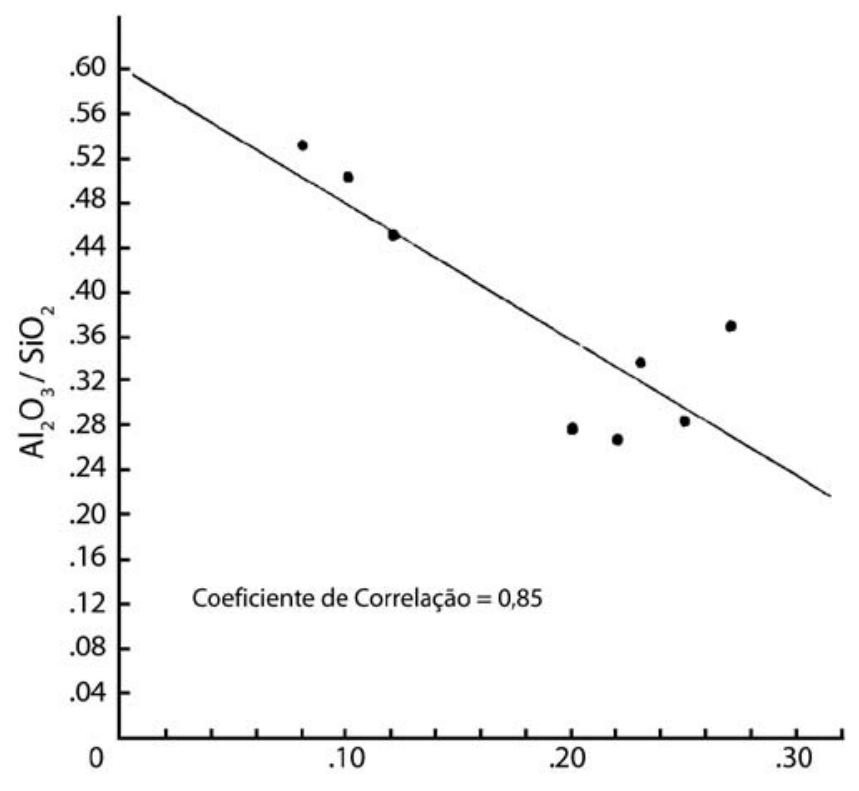

Expansão por Umidade (\%) com $8 \%$ de absorção

Figura 4: Efeito da composição na EPU [25].

[Figure 4: Effect of composition on the ME [25].]

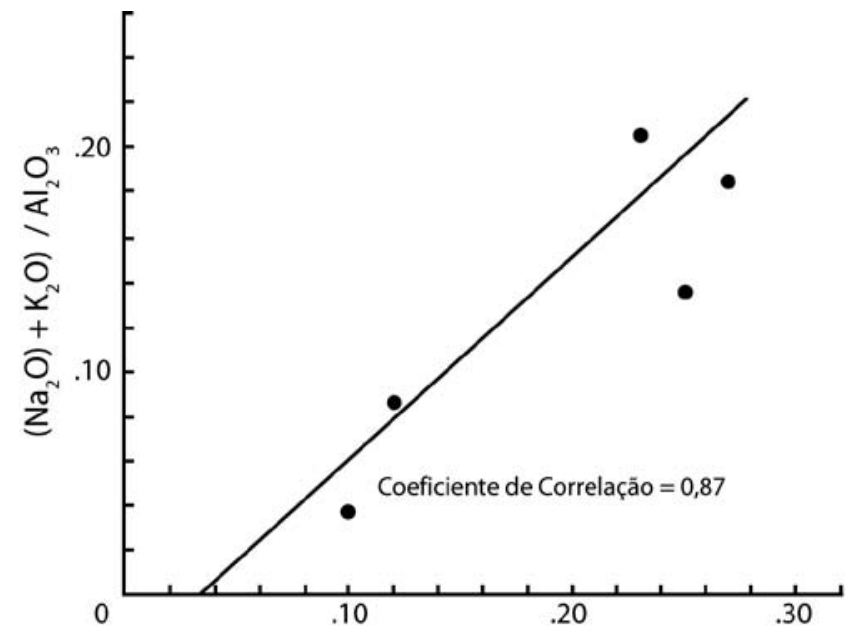

Expansão por Umidade (\%) com $8 \%$ de absorção

Figura 5: Efeito da composição na EPU [25].

[Figure 5: Effect of composition on the ME [25].]

grande proporção de fase vítrea [41] (o que provoca uma maior expansão quando do ensaio em autoclave). A adição de quartzo finamente moído [25] conduziria a um pequeno aumento da expansão, todavia desprezível se comparado com a expansão provocada pelo sódio e potássio.

O comportamento individual dos álcalis sobre o caulim também foi estudado [25] e é ilustrado na Fig. 7. Verifica-se que as séries (por série entenda-se conjunto de valores de EPU associada a adição de um elemento) do sódio (N) e do potássio (K) têm uma EPU muito mais intensa que a série padrão (P) (sem adição de sódio, potássio ou lítio). Isto pode

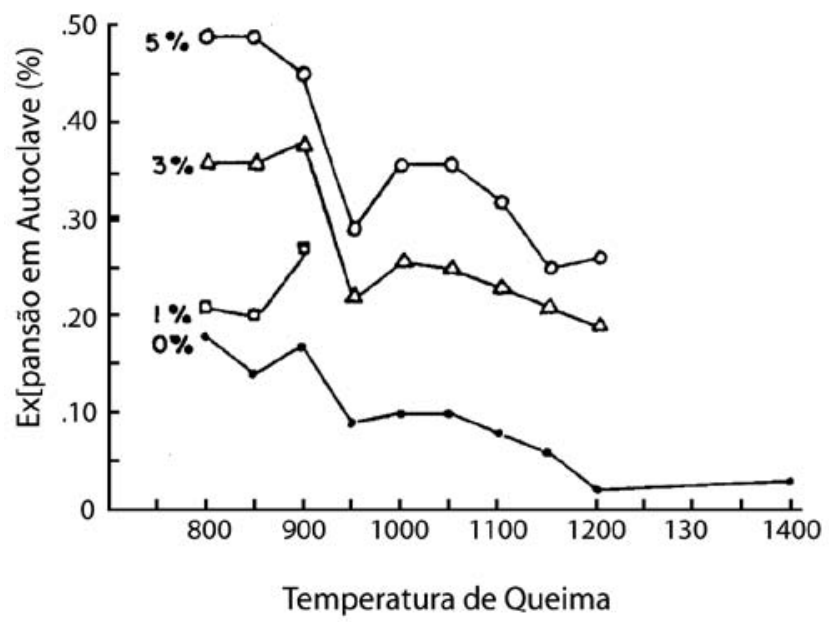

Figura 6: Efeito da temperatura de queima na EPU (autoclavagem) de caulins com adições de álcalis [25].

[Figure 6: Effect of firing temperature on the ME (autoclaving) of kaolins with alkalis additions [25].]

ser devido à dificuldade dos aluminosilicatos de sódio e potássio cristalizar, não se observando por meio da difração de raios $\mathrm{X}$ nenhum pico referente a essas fases. Já a série 
do lítio (L) apresenta a menor EPU, devido possivelmente ao desenvolvimento de mulita e um silicoaluminato de lítio (eucriptita) cristalino logo nas primeiras horas, havendo uma presença de mulita bem mais intensa na série do lítio que nas outras. Como o silicoaluminato cristaliza-se, não há mais fases amorfas e vítreas e a falta dessas reduz a expansão. $\mathrm{O}$ aumento do tempo de queima reduz a expansão provavelmente devido ao desenvolvimento de cristalinidade (que é comprovado por difração de raios X).

Nesse sentido vale salientar que estudos [54] observaram que o lítio favorece a formação da fase cristalina eucriptita, além de atuar favoravelmente sobre a transformação da metacaulinita em mulita. Nesse estudo concluiu-se que tanto o lítio, como os elementos alcalino-terrosos tendem a produzir novos compostos cristalinos e atuam no sentido de diminuir a EPU.

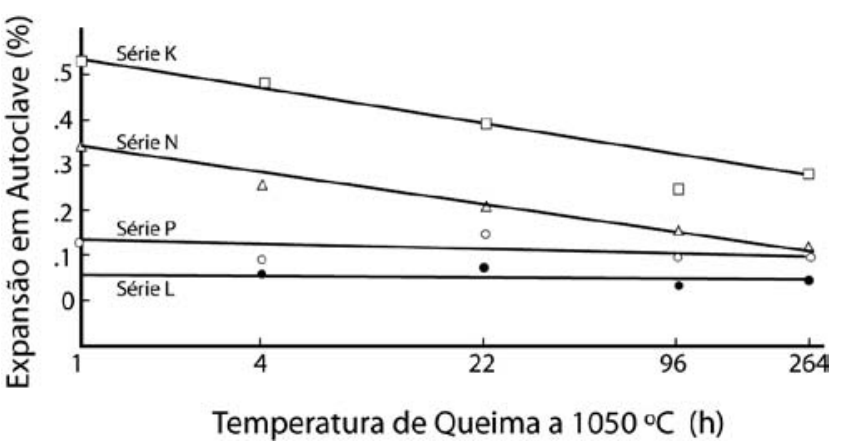

Figura 7: Efeito do tempo de queima a $1050^{\circ} \mathrm{C}$ na EPU de caulim com e sem adição de álcalis [25].

[Figure 7: Effect of firing time (at $1050^{\circ} \mathrm{C}$ ) on the ME of kaolins with and without alkalis additions [25].]

Os materiais naturais, em especial as argilas, têm uma composição mineralógica complexa além de possuir várias impurezas o que dificulta em muito a análise da influência de cada fase na EPU. Por isso pesquisadores [55] utilizaram géis puros de sílica e alumina, bem como géis de sílica e alumina coprecipitados, para simular argilas naturais livres da presença de impurezas. O efeito da composição química dos géis coprecipitados e da temperatura de queima está ilustrado na Fig. 8.

Independentemente da temperatura, pode-se observar que há um mínimo de expansão na razão sílica/alumina de 0,67 , composição da mulita. Entre as composições da sílica pura e mulita e entre as composições de mulita e alumina ocorrem máximos de expansões em razões de $\mathrm{SiO}_{2} / \mathrm{Al}_{2} \mathrm{O}_{3}$ próximas de $1,5 \mathrm{e} 0,3$, possuindo assim, grande semelhança com os resultados obtidos anteriormente [25], no que se refere à influência da razão alumina/sílica no comportamento da EPU.

Existem algumas tentativas de correlacionar a razão $(\mathrm{CaO}+\mathrm{MgO}) /\left(\mathrm{K}_{2} \mathrm{O}+\mathrm{Na}_{2} \mathrm{O}\right)$ e a EPU, todavia, enquanto alguns trabalhos encontram relações crescentes entre a referida razão e a EPU, outros autores [53] encontram coeficientes de correlação extremamente baixos, desacreditando essa relação.

A influência de outros óxidos também foi estudada [56], sendo relatado que o óxido férrico e o dióxido de titânio melhoram a resistência à umidade devido à formação de fases estáveis a semelhança do observado com a adição de cálcio, magnésio e lítio.

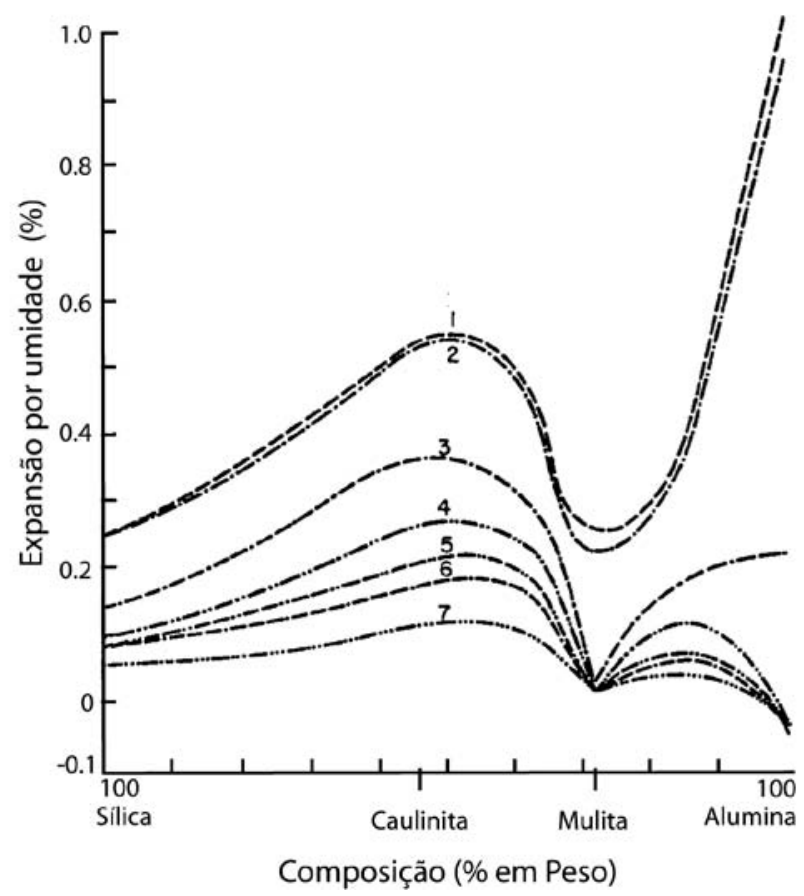

Figura 8: Efeito da composição sobre a EPU de géis coprecipitados de sílica e alumina a (1) $850{ }^{\circ} \mathrm{C}$, (2) $900{ }^{\circ} \mathrm{C}$, (3) $950{ }^{\circ} \mathrm{C}$, (4) $1000{ }^{\circ} \mathrm{C}$, (5) $1050{ }^{\circ} \mathrm{C},(6) 1100{ }^{\circ} \mathrm{C},(7) 1200{ }^{\circ} \mathrm{C}$ [55].

[Figure 8: Effect of composition on the ME of coprecipitated gels of silica and alumina: (1) $850^{\circ} \mathrm{C}$, (2) $900^{\circ} \mathrm{C}$, (3) $950^{\circ} \mathrm{C}$, (4) $1000^{\circ} \mathrm{C}$, (5) $1050^{\circ} \mathrm{C}$, (6) $1100^{\circ} \mathrm{C}$, (7) $1200^{\circ} \mathrm{C}$ [55].]

Muitas argilas da indústria cerâmica australiana e de vários outros países são compostas essencialmente por misturas de caulinita, mica e quartzo em variadas proporções [57]. Em virtude disso, vários estudos foram realizados em composições com percentuais variados de caulinita, mica e quartzo a fim de correlacionar a composição com a EPU, principalmente no que se refere aos teores de mica. Assim, observou-se que com o aumento do conteúdo de mica e da temperatura, o total de material cristalino diminuiu, havendo um aumento da fase vítrea. $\mathrm{O}$ aumento na fase vítrea com o aumento da quantidade de mica reflete-se nas propriedades cerâmicas que apresentam um aumento de retração e uma diminuição da porosidade [58]. Todavia, o que chama mais atenção para a análise de corpos contendo alto teor de mica são os resultados aparentemente contraditórios que podem ser obtidos quando da medição da EPU sofrida pelo produto, dependendo da sua temperatura de queima.

Estudos mostraram que corpos cerâmicos com 30\% de mica (matéria-prima) quando aquecidos a $500{ }^{\circ} \mathrm{C}$ como tratamento térmico de requeima, para eliminar a água adsorvida, perdiam peso e contraíam, todavia nesta mesma temperatura de requeima aqueles que foram inicialmente queimados em baixas temperaturas $\left(600-900{ }^{\circ} \mathrm{C}\right)$ mostraram uma expansão 
com a perda de água que não era reversível até temperaturas de requeima bem mais elevadas. A magnitude dessa expansão dependia da temperatura original de queima, e era zero apenas em temperaturas originais de queima superiores a $950^{\circ} \mathrm{C}$, ou seja quando a mica desidroxilada (anhydrous) é totalmente destruída. Assim, a expansão foi associada com a desidroxilação da mica, já que a mica pode se regenerar a partir da mica desidroxilada através de um processo de adsorção de água após a queima inicial [59]. Este fenômeno deve-se ao fato que a mica expande 1 a $2 \%$ na direção $c$ quando desidroxilada acima de $500{ }^{\circ} \mathrm{C}$ e retrai quando íons hidroxilas são readsorvidos pela estrutura da mica desidroxilada [43, 60].

Continuando o estudo de corpos compostos por misturas de caulinita, quartzo e mica, foi observada uma diminuição do conteúdo de quartzo com o aumento de mica moscovita, devido a reação entre o quartzo e a fase vítrea presente (associada, em muito, a presença de potássio, oriundo da mica). A fase vítrea formada nessa reação parece ser uma mistura de silicatos amorfos de ferro, alumínio e potássio e encontra-se circundando as partículas de quartzo [61]. A matriz vítrea circundante das partículas de quartzo tem uma expansão térmica diferente da expansão das partículas de quartzo e isso leva a tensões durante o resfriamento, chegando a haver a separação entre o quartzo e a matriz, provocando a formação de microtrincas ao redor do quartzo [62]. Assim, o fenômeno de adsorção de umidade pelo material amorfo é influenciado pela possibilidade de formação de microtrincas no produto, o que permitiria uma penetração mais intensa da água, aumentando o grau de EPU.

Então, tem-se que a cinética e a extensão do fenômeno de EPU dos corpos cerâmicos depende em muito da composição mineralógica das matérias primas que compõem a massa cerâmica. Todavia, deve-se ter em mente que há uma estreita relação entre a composição do corpo, a temperatura e o tempo de queima, no que se refere aos seus efeitos sobre a EPU. Já que, se a composição cerâmica não for submetida a um tempo suficiente de maturação e a uma correta temperatura de queima, as reações, ditadas pelo equilíbrio, não irão se completar e o corpo resultante estará propenso a uma elevada porosidade, grande quantidade de fases vítreas e/ou amorfas e fases residuais reativas com a água [4].

\section{Relação com a porosidade e a área especifica}

A ação da umidade depende diretamente da sua disponibilidade no ambiente, da temperatura, do tempo de contato com o corpo cerâmico e da sua estrutura. A relação entre EPU e porosidade aparente é uma correlação de "trabalho" muito conveniente, por ser a porosidade um elemento estrutural importantíssimo, muito difícil de ser eliminada completamente do corpo cerâmico e fácil de ser determinada. Todavia a porosidade pode vim a ser um indicador muito insensível a cerca da EPU, já que esta não tem, necessariamente, uma relação diretamente proporcional com a porosidade [56].

Dentro do intervalo normal de queima das indústrias cerâmicas de revestimento e tijolos têm-se observações, para a maioria dos corpos, que a EPU é diretamente proporcional à área específica $[14,36]$, e que a extensão com que as reações de "hidratação" ocorrem depende da acessibilidade da água aos compostos reativos. A acessibilidade da água e o número de zonas potencialmente "hidratáveis" são determinados em grande parte pelos poros e pela área específica dos corpos [63], ficando evidente que a contribuição mais importante, oriunda da microestrutura do material, sobre a EPU é o efeito combinado de porosidade e área específica. A porosidade e a área específica de corpos cerâmicos, quando sob a ação da água, não permanecem constantes com o decorrer do tempo (dezenas de anos), o que dificulta a correlação entre essas características e a EPU. Alguns possíveis motivos destas variações com o tempo são: a característica de auto geração de uma certa porção de volume de microporos, devido às forças de expansão provocadas pela água adsorvida, que promovem a abertura de poros anteriormente fechados, aumentando o volume total de poros; e a corrosão da fase vítrea pela água, aumentando a energia superficial da fase vítrea e abrindo poros antes fechados [24, 54, 64]. Devese ressaltar que esse aumento da estrutura aberta da fase vítrea pela água é o que explica a contínua EPU por longos períodos de tempo, o que não pode ser explicado apenas em termos da atividade superficial [65].

Um outro motivo da variação da porosidade e da área específica com o tempo é a exposição a ciclos de congelamento e descongelamento, o que faz com que a porosidade aparente tenda a aumentar em pequena quantidade, havendo um aumento da quantidade de água adsorvida nessas condições. Esse pequeno aumento de porosidade aparente é acompanhando por um pequeno aumento das dimensões do tijolo, que será mais acentuada em peças que foram queimadas em temperaturas de maturação inadequadas [18].

Estudos com materiais cerâmicos mantidos em água por vinte e um anos mostraram variações nas suas distribuição de volume de poros em função do diâmetro dos poros [66]. A fim de facilitar a comparação entre resultados, a Fig. 9 ilustra a diferença entre a porosidade das amostras originais e das amostras após serem submetidas à imersão em água, para vários diâmetros de poros. Pode-se observar que as mudanças no volume dos poros se relacionam ao tipo de corpo cerâmico. Para aqueles à base de caulinita observa-se um aumento no volume de poros com diâmetros entre 0,01 e $0,25 \mu \mathrm{m}$, nos ilíticos a faixa de aumento foi nos poros com diâmetros entre 0,05 e 0,30 $\mu \mathrm{m}$. Nos corpos a base de talco/ pirofilita a faixa de aumento foi bimodal, com diâmetros entre 0,9 e $3 \mu \mathrm{m}$ e 0,01 e $0,05 \mu \mathrm{m}$. E para a porcelana a corrosão fez-se evidente na faixa entre 0,05 e $0,75 \mu \mathrm{m}$ e abaixo de $0,01 \mu \mathrm{m}$.

Outro ponto que dificulta a comparação entre a porosidade e a EPU é a variação na temperatura e tempo de queima, já que esses fatores podem modificar a composição das fases e a estrutura de um corpo cerâmico, o que se faz, ainda mais evidente quando se deseja fazer correlações em largos intervalos de queima [67]. 


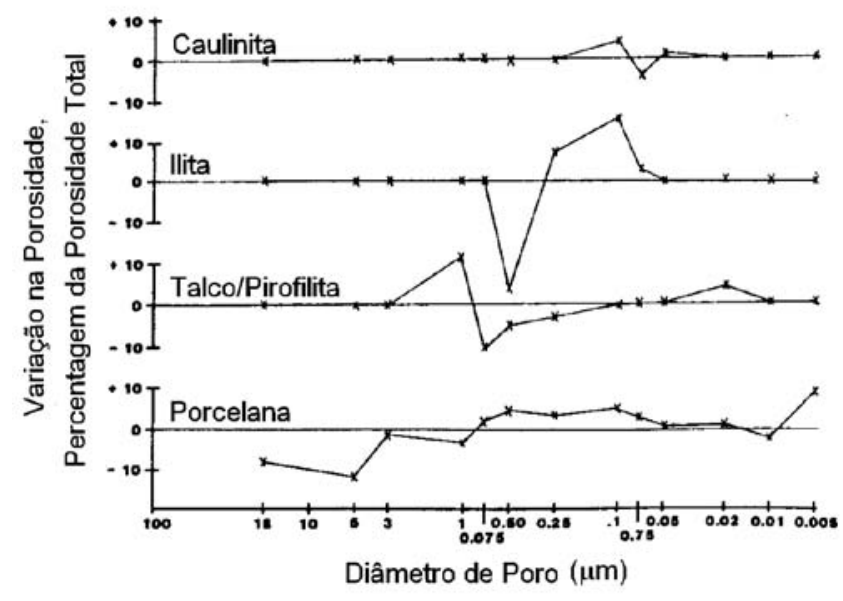

Figura 9: Variação na porosidade de espécimes imersos, comparada com a porosidade original em função do diâmetro de poros [66].

[Figure 9: Variation of the porosity of water immersed bodies versus the pores diameter [66].]

Uma das maiores dificuldades em comparar a EPU de corpos cerâmicos com suas áreas específicas está em diferenciar entre a superfície interna que está associada às superfícies ativas e aquela que não está associada às superfícies ativas, dentro das condições de exposição. Assim, é interessante analisar a distribuição das áreas específicas de acordo com a distribuição de tamanho de poros, buscando relacionar estas distribuições com a EPU. A distribuição de tamanho de poros de um corpo argiloso (composto de caulinita, mica e quartzo) está ilustrada na Fig. 10.

Se a EPU é diretamente relacionada com a porosidade, sobre o intervalo de temperatura de queima de $800-1150{ }^{\circ} \mathrm{C}$, o volume de poros que mais parece correlacionar-se a EPU é aquele com diâmetros entre 0,2 e $0,77 \mu \mathrm{m}$, que se reflete na área específica (Fig. 11), já que a melhor correspondência entre a EPU e a área específica também foi observada para os poros com diâmetros entre 0,2 e $0,77 \mu \mathrm{m}$ [68].

Com base na Fig. 11 pode-se observar que a relação entre a área específica total do corpo e sua EPU é dependente da temperatura de queima. Esta observação também foi feita por outros pesquisadores [69], que observaram um duplo efeito da temperatura de queima sobre a relação da área específica com a EPU, o de vitrificação e o de modificação composicional, tal como ilustra a Fig. 12.

Com base na Fig. 12 pode-se observar que com o aumento da temperatura de queima há uma redução da área específica, devido à vitrificação do corpo cerâmico, ao passo que a expansão inicialmente se eleva e em seguida decresce com o aumento da temperatura. Acredita-se que o aumento da EPU deve-se a modificações da composição mineralógica que resultam em fases potencialmente mais expansivas, enquanto o decréscimo está relacionado com a diminuição da área específica [69]. Estes dados vêm de encontro às observações realizadas em um dos primeiros trabalhos [70] a verificar a influência da vitrificação dos corpos sobre a sua EPU, que indicou que a vitrificação, ao provocar uma menor

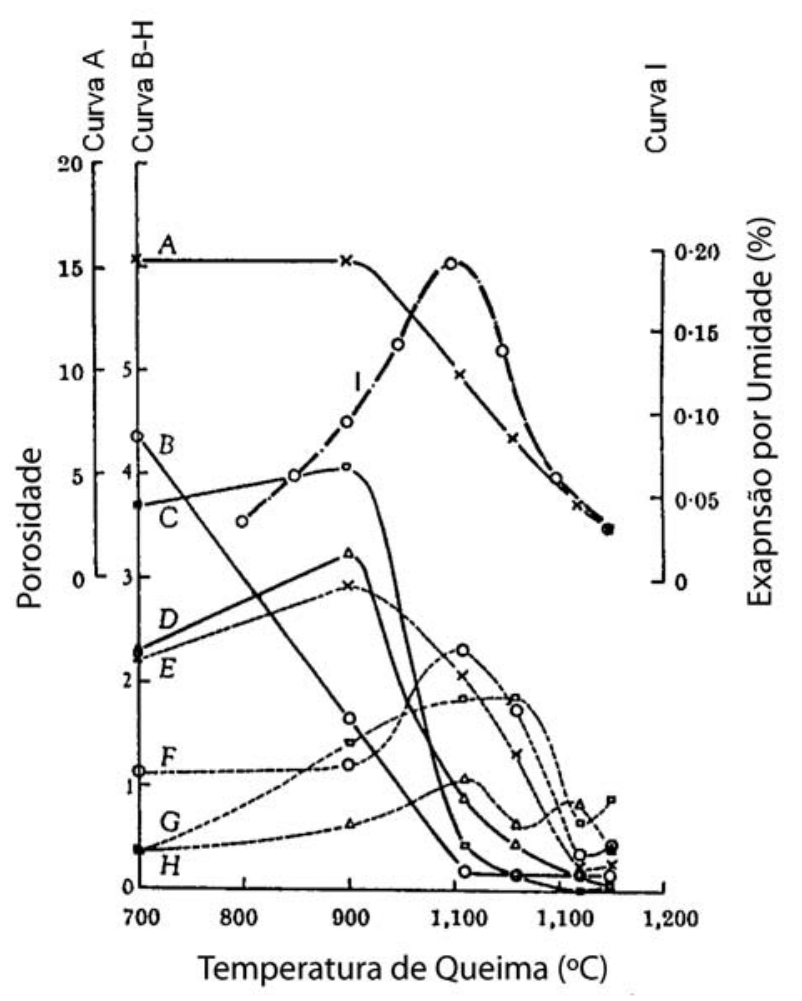

Figura 10: Porosidade e EPU versus temperatura de queima. A, porosidade total; B, poros com diâmetros $0,01-0,02 \mu \mathrm{m}$; C, poros com diâmetros 0,02-0,04 $\mu \mathrm{m}$; D, poros com diâmetros 0,04-0,08 $\mu \mathrm{m}$; E, poros com diâmetros $0,08-0,2 \mu \mathrm{m} ; \mathrm{F}$, poros com diâmetros $0,2-0,4 \mu \mathrm{m}$; G, poros com diâmetros 0,4-0,77 $\mu \mathrm{m}$; H, poros com diâmetro 0,771,66 $\mu \mathrm{m}$; I, expansão natural após 90 dias [68].

[Figure 10: Porosity and ME versus the firing temperature. A, total porosity; $B$ pores with diameters of 0.01-0.02 $\mu \mathrm{m} ; C$, pores with diameters of 0.02-0.04 $\mu \mathrm{m} ; D$, pores with diameters of 0.04-0.08 $\mu \mathrm{m} ; \mathrm{E}$, pores with diameters of 0.08-0.2 $\mu \mathrm{m} ; \mathrm{F}$, pores with diameters of 0.2-0.4 $\mu \mathrm{m} ; \mathrm{G}$, pores with diameters of 0.4-0.77 $\mu \mathrm{m} ; H$, pores with diameters of 0.77-1.66 $\mu \mathrm{m}$; I, natural ME after 90 days [68].]

absorção de água gera corpos cerâmicos com menor EPU.

Note-se que mesmo sem o efeito da modificação composicional, a diminuição da área específica em virtude de uma maior vitrificação não deve ser necessariamente encarada como fator redutor da EPU, já que o efeito de corrosão da fase vítrea, cuja severidade depende em muito do tipo de ensaio utilizado para estimar a EPU em potencial, pode vir a ser um fator predominante. Como exemplo, pode-se observar as expansões ilustradas na Fig. 12 nas temperaturas de 900 e $1150{ }^{\circ} \mathrm{C}$, onde, mesmo após uma redução altamente significativa da área específica, a EPU a $1150^{\circ} \mathrm{C}$ é pouco superior à obtida com a queima a $900^{\circ} \mathrm{C}$. O que evidencia que cuidados devem ser tomados ao se analisar dados de área específica, principalmente no que se refere ao tipo de ensaio utilizado para determinação da EPU.

\section{Relação com a absorção de água}

A absorção de água é a quantidade de água que um 


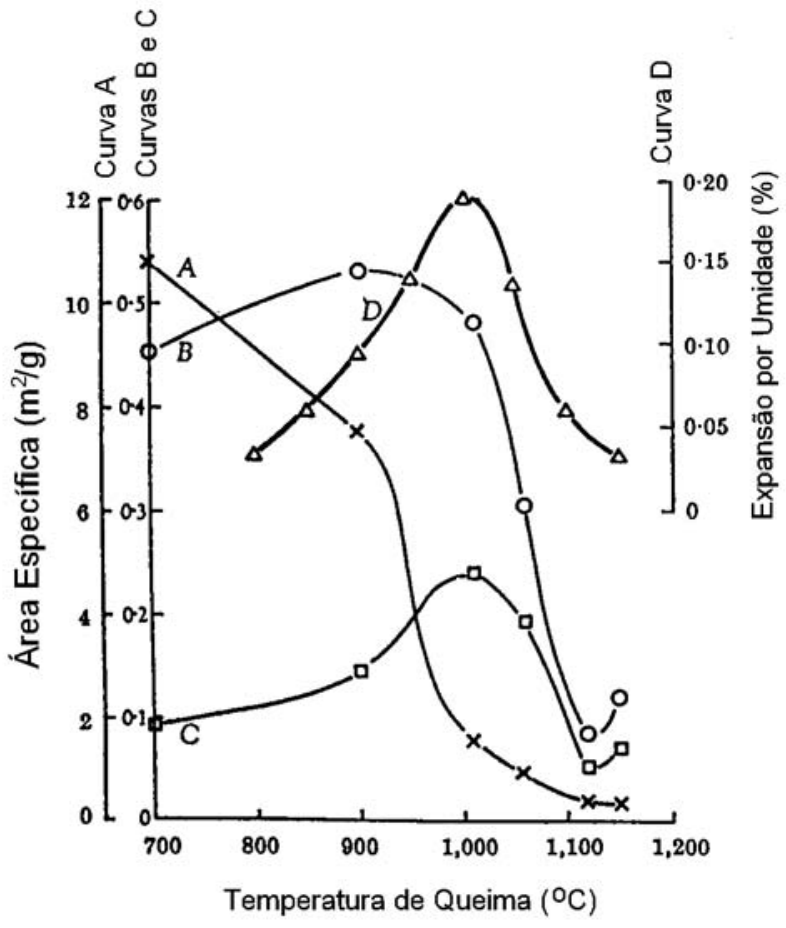

Figura 11: Área específica e EPU versus temperatura de queima: A, área específica total; $\mathrm{B}$, área específica a partir do volume de poros com diâmetros 0,08-0,7 $\mu \mathrm{m}$; $\mathrm{C}$, área específica a partir do volume de poros com diâmetros 0,2-0,77 $\mu \mathrm{m}$; D, expansão natural após 90 dias [68].

[Figure 11: Specific surface area and ME versus firing temperature: $A$, total specific surface area; $B$, specific surface area from pores with diameters of 0.08-0,77 $\mu \mathrm{m} ; C$, specific surface area from pores with diameters of 0.2-0,77 $\mu \mathrm{m} ; \mathrm{D}$, natural ME after 90 days [68].]

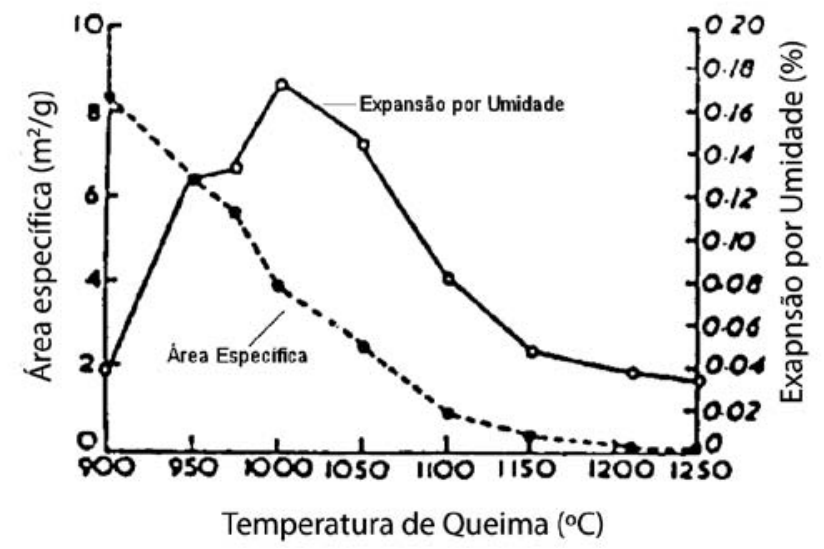

Figura 12: Relação entre a EPU (autoclave - 0,5 h e $344,5 \mathrm{kPa}$ (50 lb/in $\left.{ }^{2}\right)$, área específica e temperatura de queima de cerâmica branca [69].

[Figure 12: ME (autoclaving - $0.5 \mathrm{~h}$ at $344.5 \mathrm{kPa}\left(50 \mathrm{lb} / \mathrm{in}^{2}\right)$ ), specific surface area and firing temperature of whiteware ceramic [69].]

corpo pode absorver em contato com umidade. $\mathrm{O}$ valor da absorção é expresso em porcentagem do aumento de massa do produto em relação à sua massa seca. A capacidade de absorção de água de uma peça cerâmica fornece um indicativo da porosidade aberta do produto, ou seja, o volume total de poros comunicados com o exterior e susceptíveis de serem preenchidos com um fluido à pressão atmosférica. A absorção de água também pode indicar o grau de queima e de compactação interna do produto cerâmico e, por conseqüência, suas características mecânicas [71].

Um alto valor de absorção de água corresponde a uma estrutura porosa, enquanto que um corpo compacto possui uma baixa absorção de água. A porosidade aberta de um produto e, por conseqüência, a absorção de água, dependem da composição da massa, da densidade a verde, da distribuição granulométrica, da plasticidade de processamento, bem como das taxas de aquecimento no processo de queima e das temperaturas máximas atingidas e, se for o caso, das pressões de compactação.

Os primeiros autores a evidenciar que havia uma certa relação entre a EPU (após autoclavagem) e o ganho de peso (absorção de água), indicaram que essa não se apresentava necessariamente na forma de uma correlação linear, sendo sua forma, muito dependente da temperatura de queima e da composição do corpo cerâmico $[20,21]$. Todavia, em pesquisas posteriores [41], com corpos basicamente cauliníticos, observouse que havia uma correlação linear entre a EPU (após autoclavagem) e a absorção de água, Fig. 13. Outros autores [25], também estudando a EPU de corpos compostos por argilas predominantemente cauliníticas (EPU após autoclavagem), observaram que a correlação entre a EPU e a absorção não era necessariamente tão proporcional, como observado anteriormente [41], havendo uma proporcionalidade acentuada apenas para temperaturas maiores que a temperatura de máxima EPU, concluindo que a absorção não era um bom indicativo da EPU potencial. A Fig. 14 ilustra esses resultados.

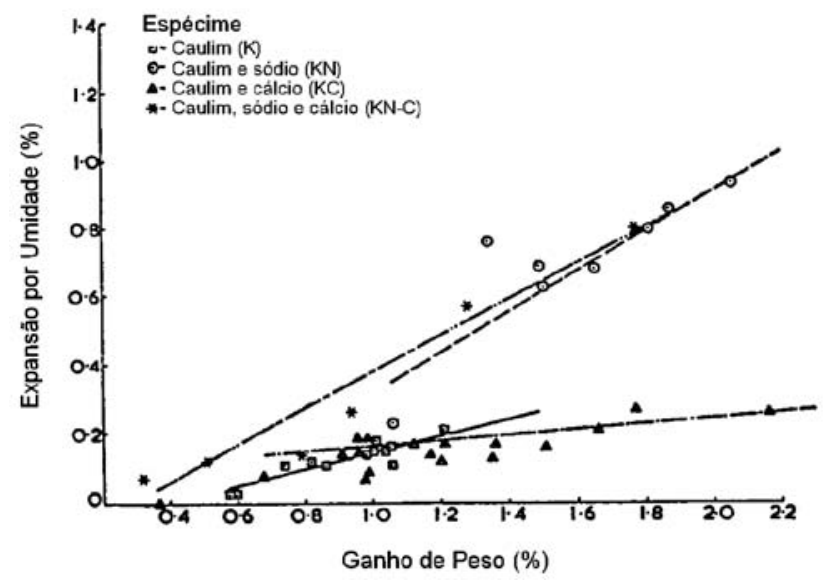

Figura 13: Relação entre EPU e absorção de água após autoclavagem por $96 \mathrm{~h}$ a $200^{\circ} \mathrm{C}[41]$.

[Figure 13: ME versus water absorption after autoclaving for $96 \mathrm{~h}$ at $200{ }^{\circ} \mathrm{C}$ [41].] 


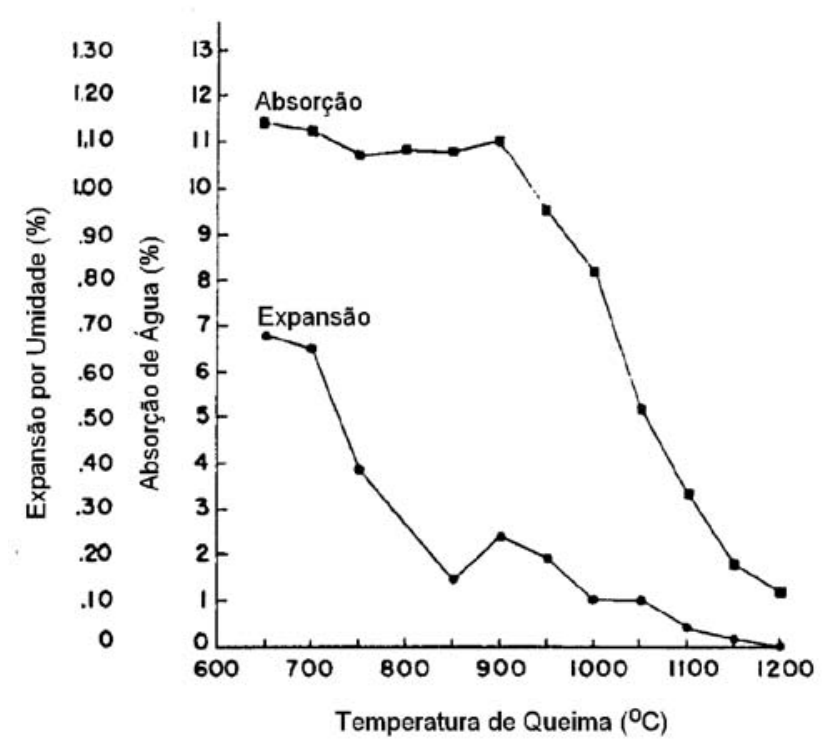

Figura 14: Efeito da temperatura de queima na EPU e absorção de água [25].

[Figure 14: ME and water absorption a function of the firing temperature [25].]

Estudando-se composições compostas por caulinita, quartzo e mica, verificou-se que para temperaturas maiores que a temperatura de “máxima” EPU, havia uma correlação diretamente proporcional, enquanto que para temperaturas inferiores a relação era linear, todavia, inversamente proporcional, Fig. 15 [43]. Em pesquisas com argilas basicamente cauliníticas (usando-se autoclavagem) chegouse a conclusões semelhantes, diferindo apenas na temperatura de máxima EPU [42]. Outros autores [72] estudando a EPU de tijolos ingleses após tratamento em ambiente saturado com vapor de água por 4 h, também observaram relações entre a EPU e absorção de água semelhantes às verificadas utilizando-se autoclavagem [42, 43].

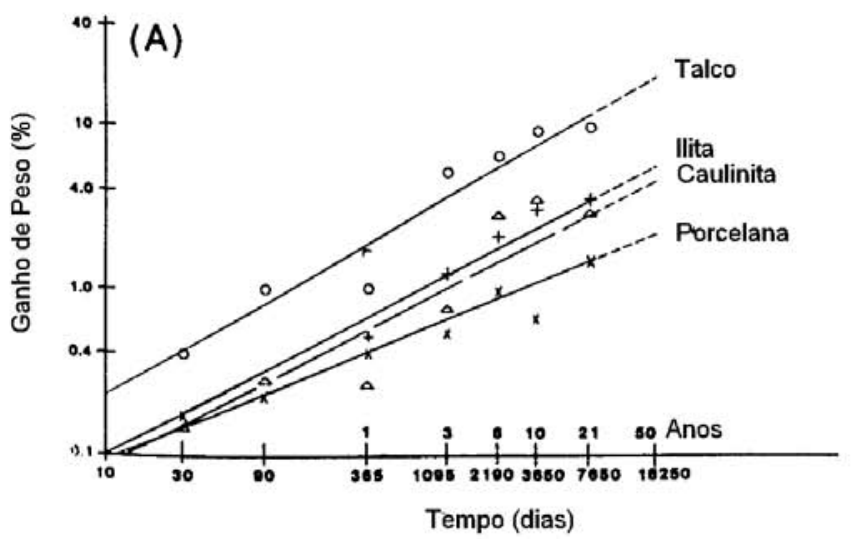

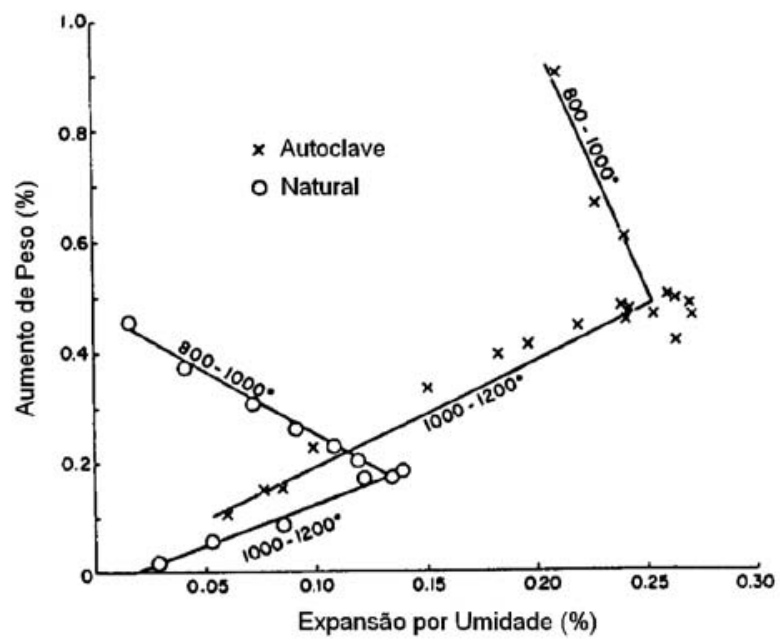

Figura 15: Relação entre aumento de peso e EPU após autoclavagem por 2 e 8 h e exposição natural por 90 dias [43].

[Figure 15: Increase in weight versus ME after autoclaving for 2 and $8 \mathrm{~h}$ and natural moisture expansion after $90 \mathrm{~d}$ [43].]

Os resultados acima ratificam que o comportamento de absorção de água e suas possíveis relações com a EPU são altamente dependentes da composição química e da temperatura de queima do corpo cerâmico, sendo observado que não há uma correlação generalizada, e que cada caso tem características próprias.

Ao se analisar a absorção de água de placas de revestimento por vinte e um anos, mostrou-se que o comportamento do corpo frente à absorção também é bastante dependente das condições de exposição a umidade [66]. Foi observado que o aumento do peso, com o tempo, é bastante pequeno para corpos submersos em água, enquanto que há um aumento gradual com os anos, para os

Figura 16: Ganho de peso de produto cerâmico (A) em atmosfera saturada, (B) imerso em água [66].

[Figure 16: Increase in weight of a ceramic body (A) saturated atmosphere, (B) water immersed [66].] 
corpos submetidos à atmosfera saturada (Fig. 16). A partir desses dados pode-se concluir que ao analisar a absorção deve ser dada especial ênfase ao tipo de tratamento ao qual o corpo foi submetido e, se possível, ter em mente o tipo de cinética que o tratamento envolve (taxa de absorção, valor da absorção inicial, etc.).

\section{CONCLUSÕES}

A expansão por umidade (EPU) de materiais cerâmicos vem sendo extensivamente estudada desde as primeiras décadas do século passado. Os motivos que despertaram o grande interesse da comunidade científica pelo fenômeno foram as constatações que danos estruturais em alvenarias na Austrália, Reino Unido e Estados Unidos e o gretamento de louças e revestimentos cerâmicos após vários anos de uso, eram conseqüência do fenômeno de EPU dos corpos cerâmicos. Os estudos desenvolvidos evidenciaram que o fenômeno de expansão está associado à redução da energia superficial da cerâmica com a adsorção da água na sua superfície. E que, por apresentar elevada área superficial e energia superficial, as fases amorfas são mais susceptíveis de apresentar elevada EPU, enquanto que as fases vítreas, apesar de possuír uma menor área superficial, podem sofrer processos de lixiviação que fazem com que sua superfície passe a apresentar elevada energia superficial, semelhantemente às fases amorfas. Com o decorrer das pesquisas observou-se que a utilização de uma formulação cerâmica adequada às características de processamento do material, privilegiando a formação de fases cristalinas, em detrimento das vítreas e amorfas, possibilitaria a minimização da EPU dos produtos finais. Nesse sentido, observou-se também que uma menor acessibilidade da água ao interior da microestrutura do material também seria uma alternativa na redução da EPU dos corpos cerâmicos. Quanto às perspectivas para estudos futuros sobre EPU, acredita-se que muitas análises serão desenvolvidas visando otimizar as formulações cerâmicas processadas em ciclos de queima rápida, a fim de minimizar a EPU dos produtos finais. Já que há uma grande tendência na utilização de ciclos de queima rápida no processamento de várias cerâmicas, tal como já ocorre com os revestimentos, e porque este tipo de queima, se não perfeitamente controlada, pode gerar peças com propensão a possuir fases amorfas e grande quantidade de fases vítreas.

\section{REFERÊNCIAS}

[1] M. Y. L. Chew, Constr. Building Mater. 13 (1999) 293. [2] L. C. Chiari, C. J. Oliveira, C. Monteiro, N. V. Forjaz, E. Biscaro, A. O. Boschi, Cerâmica Industrial 1, 1 (1996) 6.

[3] R. Bowman, Industrial Ceramics 16, 2 (1996) 89.

[4] A. M. Segadães, M. A. Carvalho, H. C. Ferreira, Ceram. Int. 29, 8 (2003) 947.
[5] Cerâmica Porto Ferreira, Cerâmica Industrial 5, 1 (2000) 7.

[6] F. E. Bernett, Am. Ceram. Soc. Bull. 55, 12 (1976) 1039.

[7] C. T. Grimm, Trans. Brit. Ceram. Soc. 82, 1 (1983) 16.

[8] F. Norton, Introdução à Tecnologia Cerâmica, Edgard Blücher e Universidade de S. Paulo, S. Paulo (1973).

[9] L. F. B. Marino, A. O. Boschi, Cerâmica Industrial 3, 1/2 (1998) 17.

[10] Centro Cerâmico do Brasil (CCB), Ensaios para Certificação de Revestimentos Cerâmicos Segundo Norma NBR 13818 (1999).

[11] H. G. Schurecht, J. Am. Ceram. Soc. 11, 5 (1928) 271.

[12] L. Mattyasovszky-Zsolnay, J. Am. Ceram. Soc. 29, 7 (1946) 200.

[13] L. Bullin, K. Green, Trans. Brit. Ceram. Soc. 53, 1 (1954) 39.

[14] R. Bowman, Ceramica Acta 5, 4-5 (1993) 37.

[15] R. Vasic, S. Despotovic, Trans. Brit. Ceram. Soc. 97, 3 (1998) 133.

[16] B. Plesingerová, M. Klapác, M. Kovalciková, Ceramics Silikaty 46, 4 (2002) 159.

[17] G. E. Merritt, C. G. Peters, J. Am. Ceram. Soc. 9, 6 (1926) 327.

[18] L. A. Palmer, J. Am. Ceram. Soc. 14, (1931) 541.

[19] T. McNeilly, Trans. Brit. Ceram. Soc. 82, 1 (1983) 14.

[20] H. G. Schurecht, G. R. Pole, J. Am. Ceram. Soc. 12, 9 (1929) 596.

[21] H. H. Holscher, J. Am.. Ceram. Soc. 14, 3 (1931) 207.

[22] C. C. Treischel, Ceramic Age 25, 2 (1935) 46.

[23] J. W. McBurney, Proc. Am. Soc. Test. Mater. 54 (1954) 1219 .

[24] A. N. Smith, Trans. Brit. Ceram. Soc. 54, 5 (1955) 300.

[25] J. E. Young, W. E. J. Brownell, J. Am. Ceram. Soc. 42, 12 (1959) 571.

[26] G. V. Cullen, E. S. Klucis, I. C. McDowall, J. Am. Ceram. Soc. 47 (1964) 415.

[27] W. F. Cole, J. Aust. Ceram. Soc. 22, 1 (1986) 45.

[28] C. M. Gomes, L. V. Amorim, A. M. Segadães, H. C. Ferreira, Anais $14^{\circ}$ Cong. Bras. Eng. Ci. Mater., S. Paulo (2000) cdrom.

[29] F. S. Miranda, L. V. Amorim, G. A Neves, R. A. Oliveira, H. C. Ferreira, Anais $44^{\circ}$ Cong. Bras. Cerâm., S. Pedro (2000) cdrom.

[30] L. F. A. Campos, R. S. Macedo, H. C. Ferreira, Anais do $43^{\circ}$ Cong. Bras. Cerâm., Florianópolis (1999) 801.

[31] A. M. Segadães, R. R. Menezes, M. A. Carvalho, H. C. Ferreira, J. Aut. Ceram. Soc. 38, 1 (2002) 20.

[32] R. R. Menezes, A. M. Segadães, H. S. Ferreira, H. C. Ferreira, Anais $46^{\circ}$ Cong. Bras. Cerâm., S. Paulo (2002) 1929.

[33] R. R. Menezes, A. M. Segadães, H. S. Ferreira, H. C. Ferreira, Anais $46^{\circ}$ Cong. Bras. Cerâm., S. Paulo (2002) 1942.

[34] R. R. Menezes, A. M. Segadães, H. S. Ferreira, H. C. Ferreira, Anais 46 Cong. Bras. Cerâm., S. Paulo (2002) 1955. 
[35] H. R. Pereira, Diss. Mestrado, Coord. Pós-grad. Eng. Quím., Univ. Fed. Campina Grande, RN (2002).

[36] R. R. Menezes, A. M. Segadães, H. S. Ferreira, H. C. Ferreira, Cerâmica 49, 310 (2003) 72.

[37] R. J. F. Bauer, F. Rago, Cerâmica Industrial 5, 3 (2000) 41.

[38] I. L. Freeman, R. G. Simth, Trans. Brit. Ceram. Soc. 66, 1 (1967) 13.

[39] R. F. Geller, A. S. Creamer, J. Am. Ceram. Soc. 24, 3 (1941) 77.

[40] J. S. Hosking, H. V. Hueber, Nature 182, 4643 (1958) 1142.

[41] A. A. Milne, Trans. Brit. Ceram. Soc. 57 (1958) 148.

[42] P. S. Boucher, J. Aust. Ceram. Soc. 23, 1 (1987) 27.

[43] W. F. Cole, J. Am. Ceram. Soc. 45, 9 (1962) 428.

[44] H. Thiemecke, J. Am. Ceram. Soc. 24, 2 (1941) 69.

[45] H. Thimecke, J. Am. Ceram. Soc. 26, 6 (1943) 173.

[46] R. T. Laird, A. A. Wickens, Trans. Brit. Ceram. Soc. 67, $12(1968) 629$.

[47] R. G. Smith, Trans. Brit. Ceram. Soc. 92, 6 (1993) 233.

[48] L. C. Chiari, C. J. Oliveira, C. Monteiro, N. V. Forjaz, E. Biscaro, L. F. Marino, A. O. Boschi, Cerâmica Industrial 1, 3 (1996) 35.

[49] C. Lira, O. E. Alarcon, M. D. M. Silveira, J. A. A. Bianchi, E. L. Honorato, L. Costa, Cerâmica Industrial 2, $1 / 2$ (1997) 27.

[50] B. E. Yekta, P. Alizadeh, Am. Ceram. Soc. Bull. 75, 5 (1996) 84.

[51] G. C. Robinson, Am. Ceram. Soc. Bull. 64, 5 (1985) 712.

[52] E. Sanchez, J. García, F. Ginés, F. Negre, Cerâmica Industrial 1, 3 (1996) 13.
[53] P. S. Boucher, Unrestrained Moisture Expansion of Unglazed Split Tiles, CSIR Research Report, Petroria, 1986.

[54] A. G. Verduch, Bol. Soc. Esp. Cerám. 4, 3 (1965) 259.

[55] T. Demediuk, W. F. Cole, J. Am. Ceram. Soc. 43, 7 (1960) 359.

[56] M. Inzigneri, E. Fusarini, Trans. VII Int. Ceram. Cong. (1960) p. 53.

[57] W. F. Cole, D. N. Crook, J. Am. Ceram. Soc. 51, 2 (1968) 79.

[58] G. W. Brindley, S. Udagawa, J. Am. Ceram. Soc. 43, 2 (1960) 59.

[59] W. F. Cole, Nature 192, 4804 (1961) 737.

[60] R. E. Grim, Clay Mineralogy, $2^{\text {nd }}$ Ed., McGraw-Hill Book, New York (1968).

[61] D. N. Crook, J. Aust. Ceram. Soc. 18, 1 (1982) 10.

[62] D. N. Crook, L. N. Clarke, R. Donaldson, J. Aust. Ceram. Soc. 20, 1 (1984) 13.

[63] J. S. Hosking, J. Aust. Ceram. Soc. 15, 1 (1979) 1.

[64] J. A. Slyh, Am. Ceram. Soc. Bull. 63, 12 (1984) 1495.

[65] F. Vaughan, A. Dinsdale, Nature 183, 4661 (1959) 600.

[66] J. A. Slyh, Am. Ceram. Soc. Bull. 64, 8 (1985) 1148.

[67] M. Cornwall, J. B. Everill, Trans. Brit. Ceram. Soc. 78, 96 (1979) R12.

[68] W. F. Cole, Nature 196, 4850 (1962b) 127.

[69] F. Vaughan, A. Dinsdale, Trans. Brit. Ceram. Soc. 61, 1 (1962) 1.

[70] G. R. Rigby, Trans. Brit. Ceram. Soc. 33 (1934) 527.

[71] S. I. Marras, I. A. Ihtiaris, N. K. Hatzitrifon, K. Sikalidis, E. C. Aifantis, J. Eur. Ceram. Soc. 20 (2000) 489.

[72] J. Lomax, R. W. Ford, Trans. Brit. Ceram. Soc. 82, 3 (1983) 79.

(Rec. 17/11/2004, Rev. 25/04/2005, Ac. 05/08/2005) 